\title{
NOISE CHARACTERISTICS AND SOUND PRESSURE LEVEL PREDICTION OF LOGGIA BALCONY IN APARTMENT
}

\author{
Afif Fajar Zakariya I Ima Defiana* I Teddy Badai Samodra
}

Department of Architecture, Institut Teknologi Sepuluh Nopember, Surabaya, Indonesia

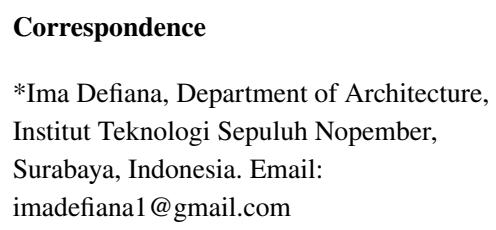

\section{Present Address}

Gedung Arstiektur, Kampus ITS Sukolilo, Jl. Raya ITS, Surabaya 60111, Indonesia

\begin{abstract}
Many residential areas are in the street class with high noise, including the apartment. Noise is often overlooked when it will have an impact on the health of residents. The balcony design in apartments can capture and even reduce noise, so this needs to be further investigated; the most widely used balcony in the apartment is a loggia type balcony. To find out the noise level of a place from a particular source such as traffic noise can be done by direct measurement. Knowing the noise level ratio, the method taken is field measurement, simulation, and mathematical calculations. The method of measuring the field using the Gunawangsa Manyar Apartment object by measuring noise levels carried out for 24 hours on the apartment's balcony, the noise level simulation method was carried out with I-Simpa, and the calculation method used a mathematical model. The results obtained are two types of noise on the apartment balcony, namely vehicle noise is steady, and vehicle noise is impulsive with noisy air-conditioner. The comparison of field measurements with simulation methods and calculations shows a high relationship so that the I-Simpa simulation method and calculation can be used to predict the desired noise level on a particular floor.
\end{abstract}

\section{KEYWORDS:}

ASJ RTN-Model 2013, I-Simpa, Noise Characteristics, Sound Pressure Level Prediction

\section{1 | INTRODUCTION}

Traffic noise in Indonesia is closely related to road class. The government sets rules for dealing with road class divisions, which indirectly limit noise on the highway because there are vehicle limits and each road class's speed. The faster the vehicle's speed, the higher the vehicle's noise level ${ }^{[1}$. The more crowded the vehicle also causes high noise on the highway, such as those found in the class III-B road, dense with vehicles with a source of noise from small to medium-sized vehicles.

Noise is often overlooked when it has an impact in the long run. Even though noise is now one of the important factors in the biophilic design concept because good acoustic quality can help eliminate stress by $37 \%$ than in noisy environments ${ }^{[2]}$. 
According to Brink et al. ${ }^{[3]}$, noise or noise with high intensity can cause various problems. Noise can disturb work peace, damage hearing, and cause communication errors. Another problem with noise is health. As in the study of Zijlema ${ }^{[4]}$, the higher the level of traffic noise increases, the heart rate, which the heart can work harder and can increase the risk of a heart attack.

This noise should not interfere with the comfort of housing. Not only low-rise residential but also high-rise. Because of the currently limited land, many high-rise buildings are built and are always exposed to noise from traffic. From observations on facades, it was seen that apartment buildings that became a trend were apartments using balconies that entered the building. This results in a high probability of getting high noise because the balcony seems to create a hole that can capture noise and lack of noise barriers. Samodra ${ }^{[5]}$ states that site barriers as noise reduction can reduce noise by up to $25 \mathrm{~dB}$. Still, we cannot use the barrier site in an apartment because the traffic noise will go directly to the balcony. The peak of noise can occur when apartment residents want natural ventilation by opening windows, but not just air entering but also unwanted sounds such as traffic noise. In contrast, according to ${ }^{6}$, there is ventilation that can be used during the day and at night.

Traffic noise can reach $90 \mathrm{~dB}$ [7. According to the Minister of Environment Decree no. 48 of 1996 concerning the maximum noise limit, occupancy is $55 \mathrm{~dB}$. Provisions for maximum noise limits differ according to time. The maximum noise limit required by $\mathrm{WHO}^{\sqrt{8}}$ in the daytime is $35 \mathrm{~dB}$, while it is $30 \mathrm{~dB}$ for the night.

In reality, noise in apartments is not limited to traffic. Still, noise is also generated from neighboring apartment units (community noise). In the research conducted by Park ${ }^{[9]}$, from 23:00 to 07:00, the apartment noise exceeds the maximum threshold required by WHO, ranging from 30-40 dB. The room noise can be heard, one of which comes from traffic, which then passes through the balcony area. This means special handling of balcony elements is needed as a noise barrier to reduce noise from outside the apartment to create acoustic comfort in space while paying attention to the difference between day and night because of different sources and noise values.

There are several methods for knowing sound propagation, including the simulation method using I-Simpa and the mathematical model ASJ RTN-Model 2013. This study compares the results of field measurements with simulation methods and calculation models to know how much the relationship between the two. It is expected that the results of this study can be used as a basis for predicting noise levels in high-rise buildings on the desired floor.

\section{2 | MATERIAL AND METHOD}

\section{1 | Traffic noise measurement}

The most commonly used environmental noise measurement is the equivalent continuous noise level (Leq) with a 24 hour time reference ( $\mathrm{T}=24$ ) or called Leq (24 hours). With an SLM that has an LTM5 recording facility, which is Leq with a measuring time every 5 seconds, measurements were carried out for ten minutes. There were 120 data to be processed with Microsoft Excel with a logarithmic formula. This method was also carried out by Rusjadi 10$]$.

As exemplified by the Minister of Environment Decree Number 48 of 1996, the measurement time can be carried out during 24-hour activities (NGOs) using the highest activity level during the day for 16 hours (LS) at intervals of $06.00-22.00$ and 8 hours of measurement must represent a specific time interval by setting at least four measurement times during the day and at night at least three measurement times.

To find out the characteristics of noise that is heard and occurs on the apartment's balcony, we installed a device. The device can be seen by direct observation and recording sounds with a recorder (Fig 1 . In this study, an assessment of the characteristics of noise was carried out by conducting a questionnaire filling method. The questionnaire was completed independently by researchers. This approach also been performed by Krimm ${ }^{111}$ from direct observation and recordings of recorders with questions that can be seen in Fig 2

It can be seen in the Fig 2 there is an assessment of the table on a scale of 1 to 5 . To noticeable to the loud indicates how hard the sound is heard in each sound source. For a sharp scale to a diffuse, it indicates how exact the sound source is, whether it is sharp enough to sound or sound faint because it blends with other noise sources. The type of sound source is divided into two: steady, continuous, and impulsive, which lasts intermittently or only occurs a few times. 


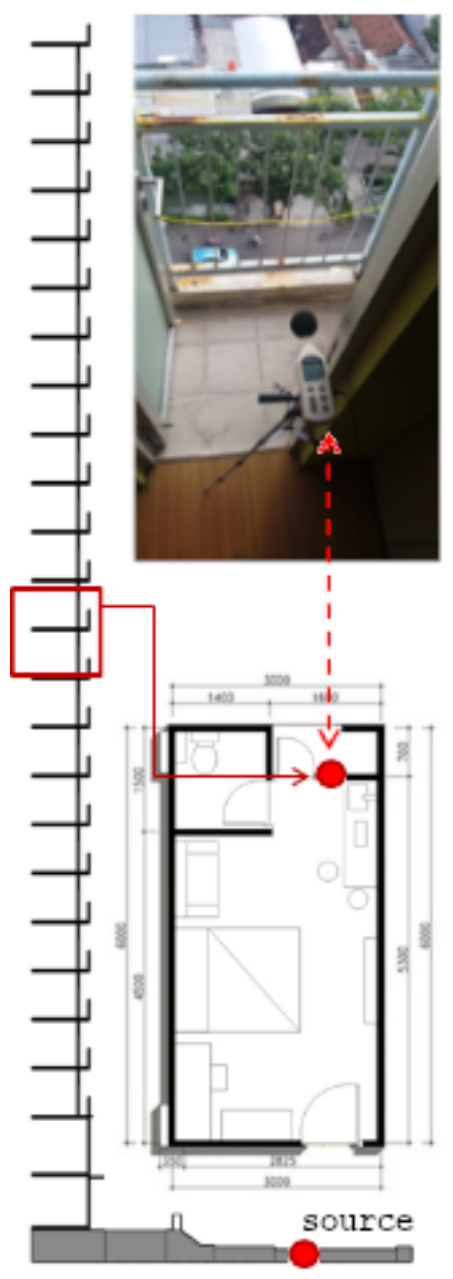

FIGURE 1 Sound pressure level measurement.

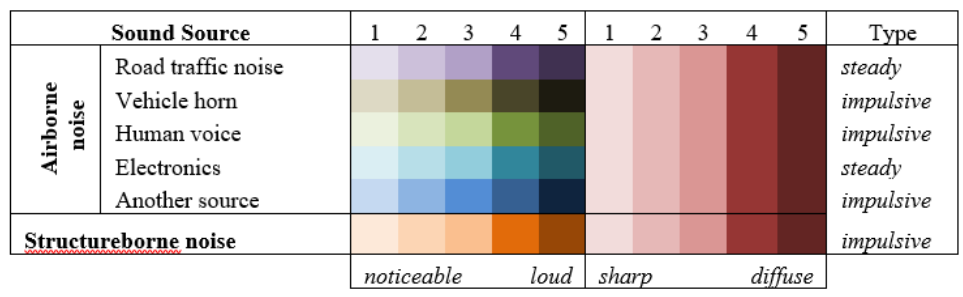

FIGURE 2 Noise pressure measurement questionnaire.

\section{2 | I-Simpa simulation}

The simulation in this study uses the I-Simpa program. This simulation program created by Nicolas Fortin is used to determine the sound propagation that occurs on the outside of the building and can be used to find out on the balcony or indoors by doing $3 \mathrm{D}$ modeling.

I-Simpa simulation was used by Picaut ${ }^{[12]}$ and Pilch ${ }^{[13]}$ in conducting simulations to predict sound propagation. Pilch ${ }^{[13]}$ says that to get more accurate results in using I-Simpa, it is not enough to apply the default material that has been provided in the program but must change the coefficient of absorption of material manually in accordance with the existing material. While Picaut ${ }^{[12]}$ says that sound propagation can be done with this program because it is based on the SPPS calculation model. 


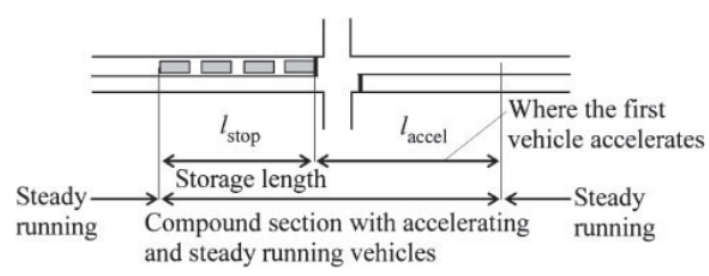

FIGURE 3 Noise that occurs on the road.

I-Simpa excellence includes: can know the sound propagation of the 3D model by determining the sound source point and the receiving point to be measured, able to analyze various acoustic parameters such as Sound Pressure Level (SPL) with different $\mathrm{dB}$ or dBA loading, sound clarity/clarity (C), Reverberation Time (RT), Early Decay Time (EDT), and stage support (ST), The outputs are in the form of $\mathrm{dB}$ and $\mathrm{dBA}$ numbers, as well as the spectrum that occurs, and can analyze complicated mass formation rooms, both indoor or outdoor.

Two algorithms can be considered ${ }^{[12]}$. The first approach is to consider that the energy of the particle is constant. In the function of the phenomena, the particle may disappear from the domain or follows its propagation: the number of sound particles decreases along the time. In the second approach, the particle energy varies according to the physical phenomena occurring during the propagation. In this case, the number of particles in the domain should be constant along the time. Since, in both cases, physical phenomena can be modeled according to probabilistic laws, both approaches are equivalent to Monte-Carlo methods. The accuracy of prediction is then dependent on the initial number of particles.

The condition of the free field is without absorption. The theoretical decrease of sound intensity from a point source, in the direction $(\vartheta, \varphi)$, is defined as follow.

$$
I(\theta, \phi)=\frac{Q(\theta, \phi)}{\pi r^{2}}
$$

$\mathrm{Q}$ is the omnidirectional point source $(\mathrm{Q}=1)$, and $\mathrm{r}$ is the distance from the start. Due to the modeling of the sound basis of the sound particle concept, particles' spatial distribution follows naturally the same decrease. Considering the atmospheric absorption, the decrease of the sound intensity after propagation of distance $r$ is defined as follow.

$$
I=I_{0} \exp -m r=I_{0} \exp -\frac{\ln 10}{10} \alpha_{\text {air }} r
$$

$I_{0}$ is the initial sound intensity, and $\mathrm{m}$ (in $\mathrm{Np} / \mathrm{m}$ ) the atmospheric absorption coefficient, which can be expressed from the atmospheric absorption coefficient $\alpha$ air (in $\mathrm{dB} / \mathrm{m}$ ).

Picaut ${ }^{[12]}$ stated, considering outdoor sound propagation, sound waves can be refracted due to atmospheric and thermic effects. The direction of propagation of a sound particle in the SPPS code is then updated at each time step, according to the celerity profile.

\section{3 | Mathematics model}

According to Sakamoto ${ }^{1]}$, to know the sound propagation from noise sources that move to the receiving area (balcony) in traffic conditions like this can be done using two methods: the viable and simplified method. The technique used in possible ways is measuring and calculating the volume, speed, and sound pressure level of each vehicle that is running, stopping and accelerating and slowing down the vehicle's speed. Due to limited time and resources, the practicable method was not carried out in this study. Another technique by Sakamoto ${ }^{[1]}$ that can be done is a simplified method. It assumes that the noise conditions that occur are from one vehicle at a constant speed and are constant, where the noise level is taken from the average noise level (Leq) at that hour. The practicable and simplified methods are not much different, as seen in Fig 3 so a simple method can be used in this study. 
The A-weighted sound pressure level $L_{A, i}(\mathrm{~dB})$ for noise propagation from the i-th source position to the prediction point is calculated. By considering attenuation due to various factors in the sound propagation from an omnidirectional point source in a semi-free field, the the sound pressure level can be calculated as follow.

$$
L_{A, i}=L_{W A, j}-8-20 \lg r_{i}+\Delta L_{c o r, i}
$$

$L_{A, i}$ is the A-weighted sound power level of a single running vehicle at the $\mathrm{i}$-th source position (dB), and $r_{i}$ is the direct distance from the $\mathrm{i}$-th source position to the prediction point $(\mathrm{m}) . L_{c o r, i}$ denotes the correction related to various attenuation factors in the sound propagation from the $\mathrm{i}$-th source position to the prediction point $(\mathrm{dB})$ and is given by

$$
\Delta L_{c o r, i}=\Delta L_{d i f, i}+\Delta L_{g r n d, i}+\Delta L_{a i r, i}
$$

where $\Delta L_{d i f, i}$ is the correction for diffraction (dB), $\Delta L_{\text {grnd }, i}$ is the correction for the ground effect (dB) and $\Delta L_{a i r, i}$ is the correction for atmospheric absorption $(\mathrm{dB})$. The suffix $\mathrm{i}$ for the source position is hereafter omitted for simplicity of notation.

The correction for diffraction due to acoustical obstacles such as noise barriers, $\Delta L_{g r n d, i}$ is calculated using $L_{d}$ as a function of the diffraction path difference. The fundamental correction term for diffraction, $L_{d}(\mathrm{~dB})$, is calculated as a function of the path difference $\delta(\mathrm{m})$ for diffraction considering the point source $\mathrm{S}$, diffraction point $\mathrm{O}$, and prediction point $\mathrm{P}$.

$$
\Delta L_{d}=\left\{\begin{array}{l}
-20-10 \lg \left(c_{\text {spec }} \delta\right) \\
-5-17.0 \cdot \sinh ^{-1}\left(c_{\text {spec }} \delta\right)^{0.414} \\
\min \left[0,-5+17.0 \cdot \sinh ^{-1}\left(c_{\text {spec }}|\delta|\right)^{0.414}\right]
\end{array}\right.
$$

Where $\delta$ is defined as a negative value when $\mathrm{S}$ is visible from $\mathrm{P}$, the function $\min (\mathrm{a}, \mathrm{b})$ gives the smallest amount of $\mathrm{a}$ and $\mathrm{b}$. cspec is the coefficient.

Sound propagating from road traffic to a receiver on the roadside is attenuated owing to the influences of ground surfaces, that is, road surfaces, road slopes, and roadside ground surfaces. The correction term $L_{\text {grnd }}$ for excess attenuation is calculated as the summation of attenuations due to all characters, independently of the kind of road surface pavement, as follow.

$$
\begin{gathered}
\Delta L_{\text {grnd }}=\sum_{i=1}^{m} \Delta L_{\text {grnd }, i} \\
\Delta L_{\text {grnd }, i}= \begin{cases}-K_{i} \lg \frac{r_{i}}{r_{c, i}} & r_{i} \geq r_{c, i} \\
-0 & r_{i}<r_{c, i}\end{cases}
\end{gathered}
$$

Where $L_{g r n d, i}$ is the attenuation [dB] due to the i-th ground surface, $K_{i}$ is a coefficient for the excess attenuation due to the ith ground surface, and $r_{i}$ is the propagation distance $(\mathrm{m})$ over the $\mathrm{i}$-th ground surface. The attenuation due to the $\mathrm{i}$-th ground surface is considered only in the range $r_{i}>r_{c, i}$.

The correction term Lair for attenuation due to atmospheric acoustical absorption is calculated, considering the standard state of the atmosphere (temperature, $20^{\circ} \mathrm{C}$; relative humidity, $60 \%$; static pressure, $101.325 \mathrm{kPa}$ ), as

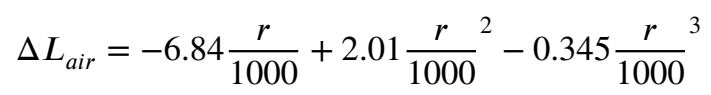

where $r$ is the distance from the source to the prediction point $(\mathrm{m})$.

\section{4 | Validation Method}

Validation or verification aims to determine the suitability of field measurements with simulations and models of calculations performed. The verification results are used as the validity of the tested model. Simulation is valid if the deviation value is 
TABLE 1 Regression value classification.

\begin{tabular}{ll}
\hline Regression Value & Relationship between Variables \\
\hline$R^{2}<0.3$ & The relationship or influence between variables is very weak. \\
$0.3<R^{2}<0.5$ & The relationship or influence between variables is weak. \\
$0.5<R^{2}<0.7$ & The relationship or influence between variables is sufficient. \\
$R^{2}>0.7$ & The relationship or influence between variables is very strong. \\
\hline
\end{tabular}

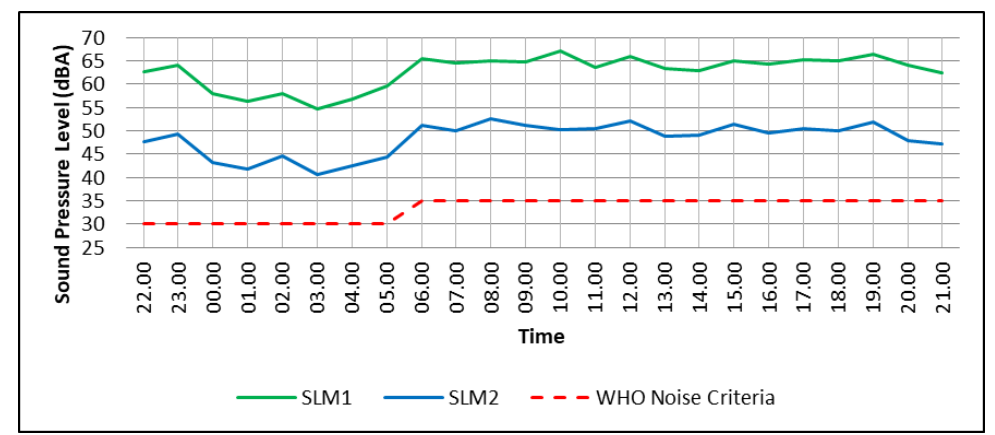

FIGURE 4 Difference value of SPL on day and night.

less than 20\%. According to Rusjadi (2011), the tolerance of difference in noise level measurement values between measuring instruments is $3 \mathrm{~dB}$.

\section{3 | RESULTS AND DISCUSSION}

\section{1 | Measurement results}

Based on the observations and discussion of field measurements, there are several conclusions related to noise levels in apartments caused by vehicle traffic conditions on the Menur Pumpungan Road. Leq measurement results for 24 hours, both weekday and weekend, show that the measurement of SLM 1 (on the balcony) during the day, the noise level is in the range of 60-70 $\mathrm{dBA}$, while the night is in the range of 50-65 dBA. For SLM 2 measurements (in apartment rooms) during the day, the noise level is $45-55 \mathrm{dBA}$, while the night is in the range of 40-50 dBA. Leq comparison can be seen in Fig. 4

The results obtained in this analysis are known that there are two types of noise. The first noise is the type of traffic noise that is steady or continuously from 05.00 to 24.00 . In contrast, the second noise characteristic is the noise level from a combination of traffic noise and $\mathrm{AC}$ noise from 1:00 to 4:00. One of the hours representing the noise conditions at 05.00 to 24.00 is at 10:00, while the noise conditions at 01.00 to 04.00 can be described at 02.00 . For more details, see Fig 2 and Table 1.

From the results of the questionnaire, it was They concluded that two types of noise occurred. The first type of noise at 05.00 24.00, can be represented from 10:00. From Fig 4 we can see that the traffic noise is steady or occurs continuously and sounds very loud. Nevertheless, because the vehicle always arrives and then other vehicles follow, the sounds are diffused or blended between one vehicle and another. Another noise is a vehicle horn and whistle, which is quite loud and sharp but only happens occasionally.

For noise occurring at 01.00-04.00, it can be represented from 2:00 a.m. Traffic noise is not steady but impulsive or happens occasionally and other dominating noise is the sound of the air conditioner (AC).

Traffic movements on the Menur Pumpungan Road are quite complex. From the results of field observations, it was found that the primary source of traffic noise with different vehicle speed conditions. The condition of the other vehicle speed in question is in the existing condition, the vehicle does not necessarily run through the area of the apartment building. But what happens is that the vehicle drives its vehicle at a steady pace, speeds up, and slows down the vehicle, and some vehicles stop to cross to enter or exit the Gunawangsa Manyar apartment. The condition of the vehicle's speed affects the noise level that occurs ${ }^{[1]}$. This 

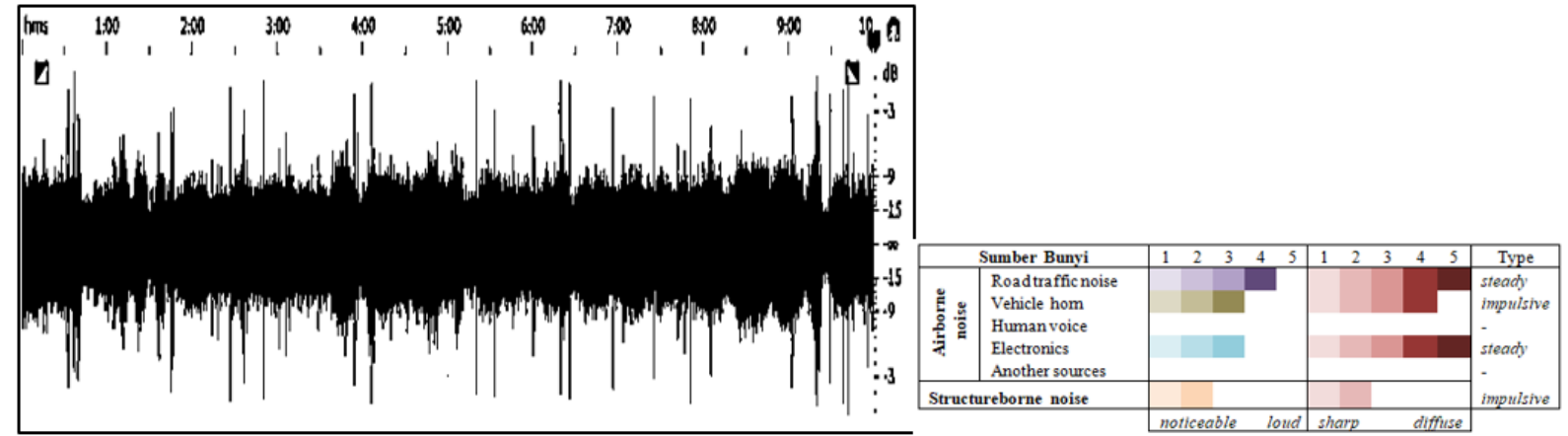

FIGURE 5 Acoustic signal and noise characteristics at 10:00 a.m.
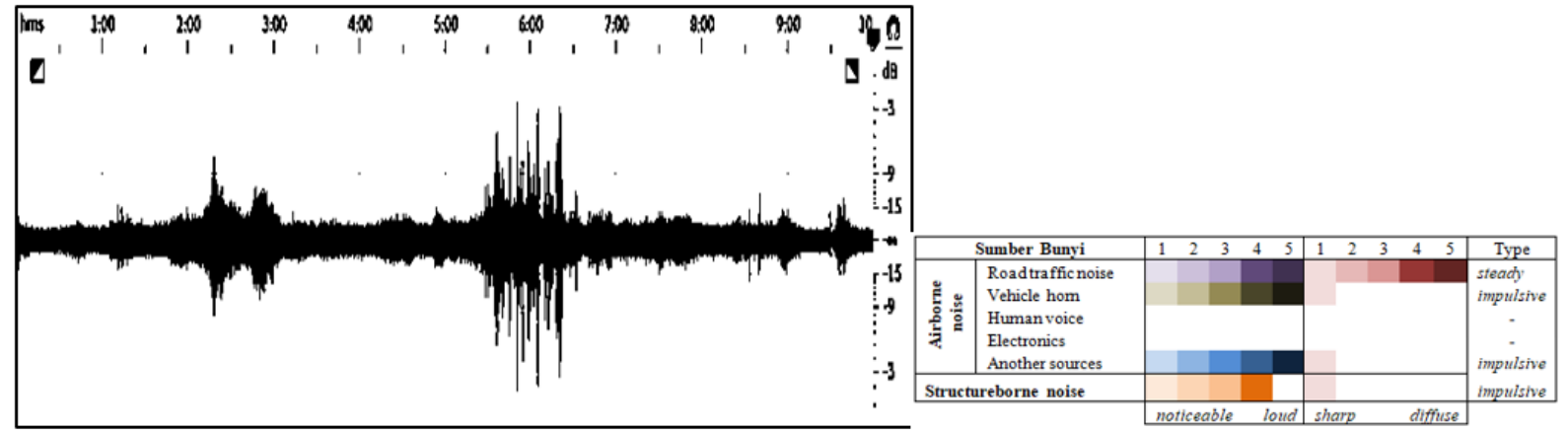

FIGURE 6 Acoustic signal and noise characteristics at 02:00 a.m.

is illustrated by the condition of the acoustic signal at 10.00 (Fig 5 , where the noise level from traffic is seen fluctuating up and down but continues to occur every time.

According to Sakamoto ${ }^{1}$, to know the sound propagation from noise sources that move to the receiving area (balcony) in traffic conditions like this can be done using a viable method and simplified method. The method used in practicable methods is measuring and calculating the volume, speed, and sound pressure level of each vehicle running, stopping, and accelerating and slowing down the vehicle's speed. However, due to limited time and resources, the method was not carried out in this study. Another method assumes that the noise conditions that occur are from one vehicle at a constant speed and are constant where the noise level is taken from the average noise level (Leq) at that specific hour.

In contrast to the noise conditions at 10:00 a.m. , at 01.00 - 04.00, the traffic noise source does not occur at any time. As seen in Fig 6 most acoustic signals show sound originating from an air-conditioner (AC), and at some point, there is an increase in noise levels originating from the vehicle, as seen in minutes 2 to 3 . There is abnormal noise in minutes 5 to 7 that are not found at other hours, namely the sound of two-wheeled vehicles whose motorcycles are being repaired and dismissed in the apartment road area.

\section{2 | Simulation results}

In this simulation, the noise source is used at 10:00 weekday. Fig 5 shows a 15th-floor balcony simulation with the results of sound pressure levels that occur on floors 3 to 25 in six different frequency bands. It can be seen that the noise level reduction from the lowest floor (3rd floor) to the highest floor (25th floor), which occurs at frequencies of 125, 250, 500, and $2000 \mathrm{~Hz}$ reaches around $2 \mathrm{~dB}$. At a frequency of $1000 \mathrm{~Hz}$, the noise level reduction from the lowest to the highest reaches $3 \mathrm{~dB}$, and at $4000 \mathrm{~Hz}$, it reaches $5 \mathrm{~dB}$. 


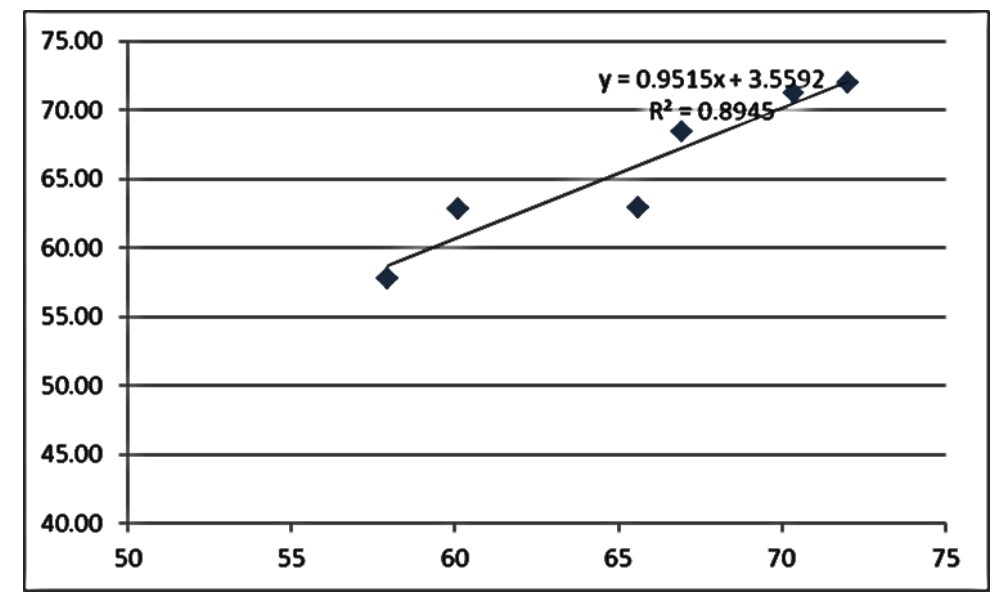

FIGURE 7 Regression analysis results of measurements and mathematical calculations.

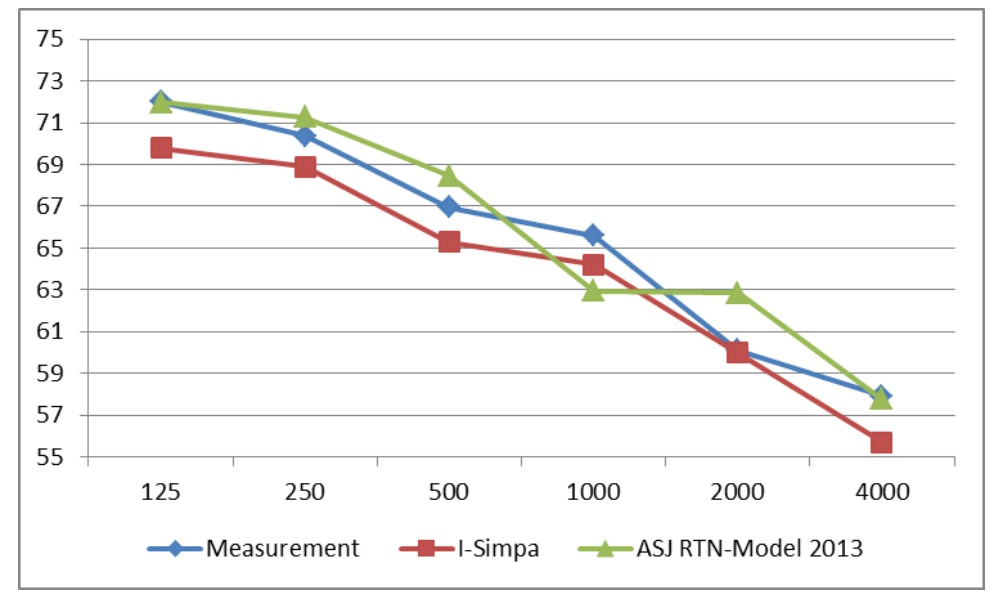

FIGURE 8 SPL comparison of measurement results, simulations and mathematical calculations.

\section{3 | Mathematics model results}

For the mathematical model, results can be seen in Fig 7 It shows that $R^{2}$ achieves a value above 0.7. This means there is a high relationship between the results of measurements and the results of mathematical calculations.

\subsection{Comparison of the measurement and simulation}

Simulation is valid if the deviation value is less than $20 \%$. According to Rusjadi ${ }^{[10]}$, the tolerance of the difference in noise level measurement values between measuring instruments is $3 \mathrm{~dB}$. Still, in the simulation results, the value does not necessarily have a difference in $3 \mathrm{~dB}$ value with the measurement results. However, it can be seen from Fig 8 that most of the simulation results have conditions that are close to the results of field measurements.

Regression values exceeding 0.7 indicate that the simulation results and field measurements are robust (Moore, 2013). Fig 9 shows the value of $R^{2}$ is above 0.7 , it means that it can be said that the comparison of the simulation results with the conditions of field measurements is robust. 


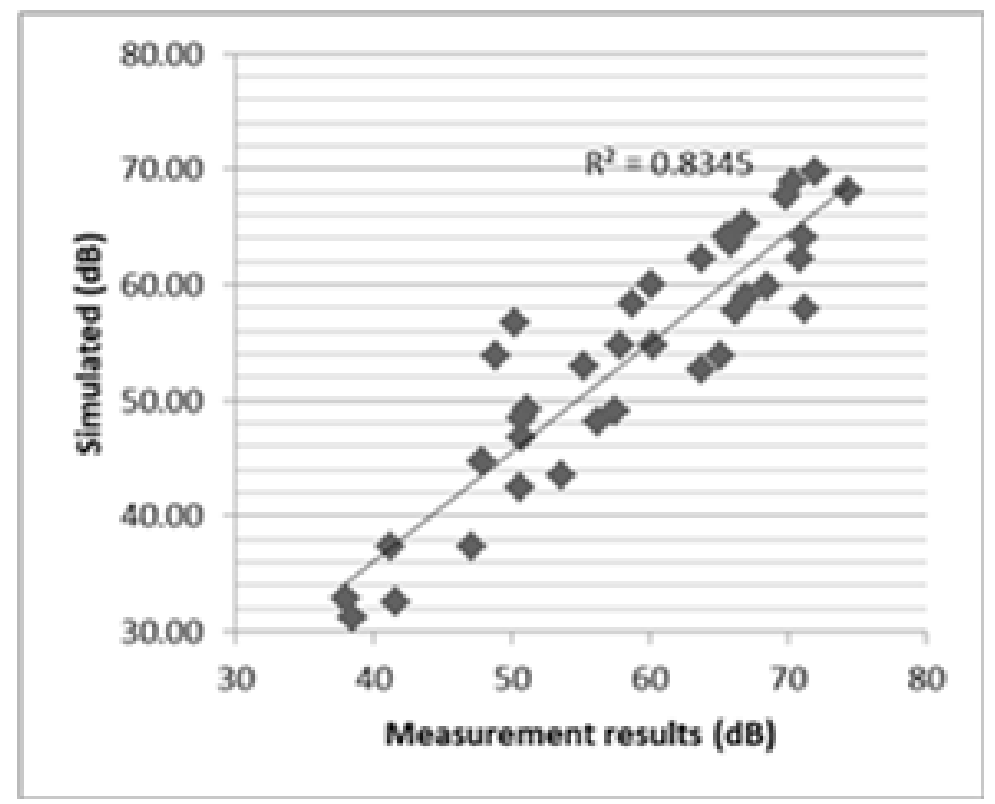

FIGURE 9 Validation of measurement and simulation results.

TABLE 2 Comparison between measurement results, simulations, and calculations.

\begin{tabular}{cccccccc}
\hline Frequency (Hz) & Measurement (a) & I-Simpa (b) & Mathematical Model (c) & $\mathbf{a - b}$ & $\sigma$ & $\mathbf{a}-\mathbf{c}$ & $\sigma$ \\
\hline 125 & 72.01 & 69.8 & 71.96 & 2.21 & 0.031 & 0.05 & 0.001 \\
250 & 70.36 & 68.9 & 71.26 & 1.46 & 0.021 & -0.90 & 0.013 \\
500 & 66.94 & 65.3 & 68.46 & 1.64 & 0.023 & -1.52 & 0.021 \\
1000 & 65.6 & 64.2 & 62.95 & 1.40 & 0.020 & 2.65 & 0.037 \\
2000 & 60.1 & 60.0 & 62.85 & 0.10 & 0.010 & -2.75 & 0.039 \\
4000 & 57.93 & 55.7 & 57.75 & 2.23 & 0.032 & 0.18 & 0.003 \\
\hline
\end{tabular}

\subsection{Comparison of the measurement and mathematical model}

According to Rusjadi ${ }^{[10]}$, the tolerance of difference in noise level measurement values between measuring instruments is 3 $\mathrm{dB}$. It can be seen in Table 1 that the difference between measurement results, simulations, and mathematical calculations; the difference does not exceed $3 \mathrm{~dB}$.

The model is considered valid if the value of the error rate does not exceed 0.05 . In this case, the standard deviation of $<5 \%$. Based on the calculation of standard deviation and regression analysis, almost all the simulation results have conditions close to the effects of field measurements. So the mathematical model carried out in this study is considered valid and can be used to predict the research design's sound pressure level/noise level.

\section{4 | CONCLUSION}

From the results of field measurements, it was found that the noise level in existing conditions did not meet WHO standards both during the day and night, even though there were differences in noise conditions. There are two types of noise characteristics that are common in apartment buildings. The first is steady/continuous both during the day and at night, which is dominated by vehicles' sound from traffic. At dawn, the noise that occurs is a combination of vehicle noise and AC noise. But when the vehicle drove, the source of a noise coming from the AC was utterly inaudible because it was dominated by vehicles passing through the apartment building. The comparison of field measurements with simulation methods and calculations shows a high relationship so that the I-Simpa simulation method and calculation can be used to predict the desired noise level on a particular floor. 


\section{References}

1. Sakamoto S. Road Traffic Noise Prediction Model "ASJ RTN-Model 2013": Report of the Research Committee on Road Traffic Noise. Acoustical Science and Technology 2015;36(2):49-108.

2. Downton P, Jones D, Zeunert J, Roös P. Biophilic Design Applications: Putting Theory and Patterns into Built Environment Practice. KnE Engineering 2017 feb;2(2):59.

3. Brink M, Schäffer B, Vienneau D, Foraster M, Pieren R, Eze IC, et al. A survey on exposure-response relationships for road, rail, and aircraft noise annoyance: Differences between continuous and intermittent noise. Environment International 2019 apr;125:277-290.

4. Zijlema W, Ca Y, Doiron D, Mbatchou S, Fortier I, Gulliver J, et al. Road Traffic Noise, Blood Pressure and Heart Rate: Pooled Analyses of Harmonized Data from 88,336 Participants. Environmental Research 2016;151:804-813.

5. Samodra FTB. Site Barrier Optimization On Integrating Thermal Comfort With Noise Propagation Control. DIMENSI (Journal of Architecture and Built Environment) 2017 jul;44(1):45-52.

6. Defiana I, Ekasiwi SNN, Satwiko P. Canyon Design as A Potential for Night Ventilation on Warm Humid Tropic Housing Estate. International Journal of Academic Research 2012;4(5).

7. Debnath A, Singh PK. Environmental traffic noise modelling of Dhanbad township area - A mathematical based approach. Applied Acoustics 2018 jan;129:161-172.

8. Clark C, Paunovic K. WHO environmental noise guidelines for the european region: A systematic review on environmental noise and cognition. International Journal of Environmental Research and Public Health 2018 feb;15(2).

9. Park SH, Lee PJ, Lee BK. Levels and Sources of Neighbour Noise in Heavyweight Residential Buildings in Korea. Applied Acoustics 2017 may;120:148-157.

10. Rusjadi D, Palupi M. Kajian Metode Sampling Pengukuran Kebisingan dari Keputusan Menteri Lingkungan Hidup No. 48 tahun 1996. Jurnal Standardisasi 2011;13(3):176-183.

11. Krimm J. Acoustically effective façades. Architecture and the Built Environment 2018;16:1-212.

12. Picaut J, Fortin N. SPPS, a Particle-Tracing Numerical Code for Indoor and Outdoor Sound Propagation Prediction. Societe Francaise d'Acoustique, Acoustics 2012 2012;p. 1417-1422. https://hal.archives-ouvertes.fr/hal-00810894\{\%\}0Ahttps: //hal.archives-ouvertes.fr/hal-00810894/

13. Pilch A. Optimization in the Validation of the Room Acoustic Model. Proceedings of EuroRegio 2016;p. 1-10. http: //www.sea-acustica.es/fileadmin/Oporto16/195.pdf

How to cite this article: Zakariya A.F., Defiana I., Samodra T.B., (2020), Noise Characteristics and Sound Pressure Level Prediction of Loggia Balcony in Apartment, IPTEK The Journal of Technology and Science, 31(2):178-187. 